\title{
Optimization of Microgrid Using Quantum Inspired Evolutionary Algorithm
}

\author{
Ebrahim Zare juybari \\ Mazandaran University of Science and Technology (USTMB), Babol, Mazandaran, Iran \\ E-mail: ebrahim.zare.juybari@gmail.com \\ Seyed Mehdi Hosseini \\ Department of Electrical and Computer Engineering, Babol Noshirvani University of Technology, Babol, Iran \\ E-mail: mehdi.hosseini@nit.ac.ir
}

\begin{abstract}
This paper presents a generalized formulation for determining the optimal operating strategy and cost optimization scheme as well as reducing the emissions of a MicroGrid (MG). In this article a microgrid including a wind turbine, pv array and a CHP system consisting of fuel cells and a microturbine is studied and then the modeling of various DERs is conducted and the objective functions and constraints are developed. The model takes into consideration the operation and maintenance costs as well as the reduction in emissions of $\mathrm{NOx}, \mathrm{SO} 2$, and $\mathrm{CO} 2$ In the end the Quantum-Inspired Evolutionary Algorithm is employed to solved the optimal model and an operation scheme is achieved while meeting various constraints on the basis of tariff details, equipment performance, weather conditions and forecasts, load details and forecasts and other necessary information and then the economic costs and environmental impacts are analyzed and a conclusion that the QEA can achieve high environmental benefits and spend as low operation cost as possible. according to power Output functions and cost function of the various units , can be achieve to minimize cost.
\end{abstract}

Index Terms - Quantum-Inspired Evolutionary Algorithm, Microgrid, Optimization

\section{INTRODUCTION}

Optimization techniques should be employed for deregulation of the power industry, allowing for the best allocation of the distributed generation (DG). The advancement in technology and a desire of the customers for cheap and reliable electric power has led to an increased interest in distributed generation. The issues related to reliability and maintenance has impeded the penetration of DG resources in distribution systems. One solution is known as microgrid which integrates various distributed energy resources (DER) close to customers with control units and power conversion units. Cheaper and greener electricity can be produced by viewing a unified microgrid as a system of supply and demand and optimizing the dispatch of DERs inside the microgrid[1]. Significant researches have been carried out to model the microgrid and optimize the costs of fuel, operation and maintenance and start-up costs, as well as the emission costs. Literature [2-5] presented the economic dispatching model of microgrid with considering some uncertainties impacting on the microgrid economic operation, such as electricity prices, energy demand, and environmental factors and alike by single-objective optimal technique. Literature [6-8] launched the economic dispatching models of microgrid to optimize the cost as well as the emissions and solved them with different multiobjective algorithms. However the articles above did not consider combined heat and power system (CHP), and as known, CHP with renewable energy generation is an important form of microgrid with higher efficiency and lower costs. The economic operation of the CHP system composed of wind power and PEMFC was studied using the evolutionary algorithm, and the results of four cases were compared in which recovery heat was dispatched differently [9]. Research of a CCHP system consisting of gas turbine and batteries was carried out in [10], and got the conclusion CCHP system with storage functions had obvious advantages, and the efficiency of the system decreased gradually with the reduce of load, however problems of operating cost were not considered. In the literature[11] a microgrid including wind energy, pv, heat recovery boiler and battery is studied and a optimal model is built to deal with the economic operation of available power resource and formulate the 24-hours' work schedule on the basis of predicting the next 24-hours' wind nergy and PV power, power and heat demand, but battery capacity is not considered. Based on the researches above, this paper will establish a economic dispatching model of microgrid, in which photovoltaic arrays, a wind turbine, batteries and a CHP system consisting of fuel cells and a microturbine are included. The Quantum-Inspired Evolutionary Algorithm is used to solve the optimal model and an operation scheme is achieved while meeting various constraints on the bas is of tariff details, equipment performance, weather conditions and forecasts, load details and forecasts and other necessary information.

\section{COMPONENTS MODELING}

\section{A. Wind turbine}

Wind turbine is used in the system of electrical generation to convert kinetic energy from the wind into 
mechanical energy and then the mechanical energy is used to produce electricity. Generally the power generated by wind generator is influenced by air density, wind speed, the size of wind turbine and a parameter named $\mathrm{P}_{\mathrm{C}}$. equation below shows the formula[12]:

$$
P_{W T}=\frac{1}{2} \rho^{*} \pi R_{W T}^{2} * V^{3} * C_{P}
$$

Where $\mathrm{W}_{\mathrm{TP}}$ is the quantity of power generated by wind turbine, $\rho, V, R_{W T}$ are the air density, wind speed, and the blade radius of the turbine, and $\mathrm{P}_{\mathrm{C}}$ represents the wind energy utilization efficiency.

When the installation site and the type of wind turbine are fixed, we can hold that the air density and the blade radius are constant. So according to the power performance test report for the wind turbine selected the actual relationship between $\mathrm{W}_{\mathrm{TP}}$ and $\mathrm{V}$ can be fitted into a function with MATLAB as follows:

$$
\begin{aligned}
& P_{W T}=0, V<V_{c i} \\
& P_{W T}=a V^{3}+b V^{2}+c V+d, V_{c i}<V<V_{r} \\
& P_{W T}=P_{r}, V_{r}<V<V_{c o} \\
& P_{W T}=0, V>V_{c o}
\end{aligned}
$$

Where $P_{r}, V_{r}, V_{c i}, V_{c o}$, are the rated power, rated wind speed, cut-in and cut-out wind speed respectively. Moreover the constants a,b,c and d depend on the type of WT and the installation site. The type of wind turbine in this article is selected as AOC 15/50 made by Seaforth Energy Inc and the parameters used to model the power output-wind speed curve are as follows:

$$
\begin{aligned}
& V_{c i}=5.26 \mathrm{~m} / \mathrm{s}, V_{r}=14.68 \mathrm{~m} / \mathrm{s}, V_{c o}=22.40 \mathrm{~m} / \mathrm{s} \\
& P_{r}=50 \mathrm{KW}, a=-0.0609, b=1.7882, \\
& c=-10.8347, d=16.3773
\end{aligned}
$$

\section{B. PV array}

A photovoltaic array is a linked collection of solar panels to convert the sunlight into electricity for a single module cannot produce enough power to meet requirements generally. PV Array generates electricity with no moving parts, operate quietly with no emissions, and require little maintenance. The output power of the module is [13]:

$$
P_{p v}=P_{S T G} G_{I N G} / G_{S T G}\left(1+K\left(T_{c}-T_{r}\right)\right)
$$

Where $P_{P V}$ is the output power of the module at irradiance $G_{\mathrm{ING}}$, and $\mathrm{P}_{\mathrm{STC}}$ is the module maximum power at standard tests condition. $\mathrm{T}_{\mathrm{C}}, \mathrm{T}_{\mathrm{R}}$ are the ambient temperature and the reference temperature respectively, $\mathrm{K}$ is a coefficient that relates power out with the temperature. In the microgrid studied in this article the maximum power of the $\mathrm{pv}$ array measured in STC is $\mathrm{P}_{\mathrm{TSC}}=25 \mathrm{KW}, \mathrm{K}=0.0167$.

\section{CHP System}

Combined Heat and Power(CHP) is the use of a heat engine or a power station to simultaneously generate both electricity and useful heat and can improve the efficiency a lot. Inside the CHP, the Micro turbine is a top priority for its low level of emissions and compatibility and the Fuel Cell technology is gaining attention because it offers the high efficiency and low level of emissions. The high temperature fuel cells such as the Solid Oxide Fuel Cell and the Molten Carbonate Fuel Cell are considered to have highest potential for cogeneration.

SOFC is an electrochemical conversion device that produces electricity directly from oxidizing a fuel that has a solid oxide or ceramic, electrolyte. Advantages of this class of fuel cells include high efficiency, long-term stability, fuel flexibility, low emissions, and relatively low cost. The efficiency of the FC refers to the ratio of the stack output power to the input energy content in the natural gas and it is normally calcu lated as the ratio of the actual operating voltage of a single cell to the reversible potential[14]. A typical efficiency curve is needed to model the FC and the fuel cost for the FC can be calculated as follows:

$$
C_{F C}=C_{n l} \sum \frac{P_{j}}{n_{j}} * \frac{1}{L H V}
$$

where $C_{n l}$ is the natural gas price to supply the $\mathrm{FC}, \mathrm{P}_{\mathrm{j}}$ is the net electrical power produced at interval $j$, and $n_{j}$ is the cell efficiency at interval $\mathrm{j}$ and LHV is lower heating value of fuel and the maximum power output of the fuel cell in this article is $100 \mathrm{KW}$.

The microturbine in the microgrid studied is selected as Capstone Model C65.The efficiency of the MT increase with the increase of the supplied power and the MT fuel cell is

$$
C_{M T}=C_{n l} \sum \frac{P_{j}}{n_{j}} * \frac{1}{L H V}
$$

where $C_{n l}$ is the natural gas price to supply the MT, $P_{J}$ is the net electrical power produced at interval $\mathrm{j}$, and $\mathrm{n}_{\mathrm{J}}$ is the cell efficiency at interval $\mathrm{j}$ and LHV is lower heating value of fuel. The specific re lationship between $P_{J}$ and $n_{J}$ can be achieved by interpolating the given data from manufacturer.

\section{Battery Storage}

Storage battery is a group of one or more electrochemical cells and State of Charge (SOC) is defined as the available capacity expressed as a percentage of some reference. For battery storage in microgrid, the constraints are in [4].

$$
\begin{aligned}
& P_{+} \leq\left(0.2 * V_{s y s} * U_{b a t t}\right) / \Delta t \\
& P_{-} \leq\left(0.2 * V_{s y s} * U_{b a t t}\right) / \Delta t
\end{aligned}
$$

Where $\mathrm{P}_{+}$and $\mathrm{P}_{-}$, are the maximu $\mathrm{m}$ allowable charge and discharge power of battery in $\Delta \mathrm{t}, \mathrm{V}$ sys is the system voltage, $\mathrm{U}$ batt is the battery capacity in $\mathrm{AH}$. 
And SOC of battery can be obtained through $\mathrm{SOC}=\mathrm{SOC}_{-}$ini $+\mathrm{P}_{+}-\mathrm{P}_{\text {- }}$, for a long life of batteries, the constarints can be set as $20 \%<$ SOC $<100 \%$.

\section{PROPOSED OBJECTIVE FUNCTION}

This article aims to develop a 24-hour dispatching scheme of various distributed resources in the microgrid to minimize the economic costs and environmental costs while meeting the electricity load and heat load of customers. Assume the wind turbine and photovoltaic system have little operation\& maintenance cost, the two objective functions can be presented as follows [15]"

$$
\begin{gathered}
C(P)=\sum_{T}\left(\begin{array}{c}
C F_{F C}+C F_{M T}+O M_{F C} \\
+O M_{M T}+B C-S E
\end{array}\right) \\
E(P)=\sum_{i=1}^{N}\left(\begin{array}{c}
10^{-2}\left(\alpha_{i}+\beta_{i} P_{i}+\gamma_{i} P_{i}^{2}\right) \\
+\delta_{i} \exp \left(\theta_{i} P_{i}\right)
\end{array}\right)
\end{gathered}
$$

Where $\mathrm{C}(\mathrm{P})$ and $\mathrm{E}(\mathrm{P})$ are the objects of economic costs and emission level, $\mathrm{CF}_{\mathrm{FC}}, \mathrm{CF}_{\mathrm{MT}}, \mathrm{OM}_{\mathrm{CF}}, \mathrm{OM}_{\mathrm{MT}}$, are the fuel cost and the operation \& maintenance cost of fuel cells and microturbine respectively, $\mathrm{BC}$ and $\mathrm{SE}$ are the cost of buying electricity and the earning of selling electricity tomacro grid, $\alpha_{i}, \beta_{i}, \gamma_{i}, \delta_{i}, \theta_{i}$ are nonnegative coefficients of the ith generator emission characteristics. The fuel cost $\mathrm{CF}_{\mathrm{FC}}, \mathrm{CF}_{\mathrm{MT}}$, can be obtained through the given models of distributed generators above and the operating and maintenance costs $\mathrm{OM}$ is assumed to be proportional to with the power output, and the proportional constant is available in literature [4].

\section{QUANTUM-INSPIRED EVOLUTIONARY ALGORITHM}

In this section, the Q-bit representation, the principle of QEA[18], and the QEA approach in are presented below.

\section{A. Q-bit Representation}

The structure of a Q-bit is as follows:

$$
\left[\begin{array}{l}
\alpha \\
\beta
\end{array}\right]
$$

where $\alpha$ and $\beta$ is a pair of complex numbers. Two states, $|0\rangle$ and $|1\rangle$, can be represented by such a Q-bit. $|\alpha|^{2}$ and $|\beta|^{2}$ indicate the probability of the Q-bit to be and, respectively, which satisfy $|\alpha|^{2}+|\beta|^{2}=1$. In QEA-UC, $\alpha$ and $\beta$ are assumed to be real numbers.

A Q-bit individual is a form of Q-bit group. For example, a Q-bit individual of a string form is as follows:

$$
\left[\begin{array}{ccccc}
\alpha 1 & \alpha 2 & \alpha 3 & \ldots & \alpha m \\
\beta 1 & \beta 2 & \beta 3 & \ldots & \beta m
\end{array}\right]
$$

Where $|\alpha|^{2}+|\beta|^{2}=1, \mathrm{i}=1,2, \ldots, \mathrm{m}$.

\section{B. Quantum-Inspired Evolutionary Algorithm}

QEA is implemented by the initialization, observation, and updating of the Q-bit individuals. The procedure of QEA is as follows [18],[19]

1 . Set $\mathrm{t}=0$ where is a generation counter.

2. Initialize $\mathrm{Q}-\mathrm{bit}$ individual group $\mathrm{Q}(\mathrm{t})$, where $Q(t)=\left[q_{1}^{t}, q_{2}^{t}, \ldots, q_{G}^{t}\right] \quad, \quad \mathrm{G} \quad$ is $\mathrm{Q}-\mathrm{b}$ it individual population size, and $q_{g}^{t}$ is the gth Q-bit individual at generation $\mathrm{t}$ for $\mathrm{g}=1,2, \ldots, \mathrm{G}$.

3. Determine a binary solution group $X(t)$ by observing $\mathrm{Q}(\mathrm{t})$, where $X(t)=\left[X_{1}^{t}, X_{2}^{t}, \ldots, X_{G}^{t}\right]$.

The observation process is to determine binary solutions from Q-bit individuals. When a Q-bit $[\alpha \beta]^{T}$ is observed, its corresponding binary character $\mathrm{A}$ can be determined by comparing $|\beta|^{2}$ to a uniformly distributed random number in $[0,1]$, and

$$
A= \begin{cases}1, \operatorname{random}[0,1]<|\beta|^{2} \\ 0, & \text { otherwise }\end{cases}
$$

Thus, a binary solution $X_{G}^{t}$ can be obtained after all the Q-bits in a Q-bit individual $q_{g}^{t}$ have been observed.

4. Evaluate $\mathrm{X}(\mathrm{t})$ and store the best solution in $\mathrm{X}(\mathrm{t})$ into $\mathrm{B}(\mathrm{t})$.

5. Set $\mathrm{t}=\mathrm{t}+1$.

6. Determine $\mathrm{X}(\mathrm{t})$ by observing $\mathrm{Q}(\mathrm{t}-1)$

7.Evaluate $\mathrm{X}(\mathrm{t})$ and store the best solution among $\mathrm{X}(\mathrm{t})$ and $\mathrm{B}(\mathrm{t}-1)$ into $\mathrm{B}(\mathrm{t})$

8. Update using Q-gates:

Q-bit individuals are updated by using Q-gates. A Qgate is a variation operator of QEA to update the Q-bits, and the updated Q-bit at generation should meet the normalization condition,

$$
|\alpha|^{2}+|\beta|^{2}=1
$$

Rotation gates areconsidered in QEA. The rotation gate and $U\left(\Delta \theta^{\mathrm{t}}{ }_{\mathrm{ji}}\right)$

Where $\Delta \theta^{\mathrm{t}} \mathrm{ji}$ is a rotation angle which determines the magnitude and direction of rotation. the polar plot of the rotation gate for Q-bit individuals.

At generation, the rotation angle $\Delta \theta_{\mathrm{ji}}^{\mathrm{t}}$ is updated. according to the criteria summarized in Table 1, where $\mathrm{x}_{\mathrm{ji}}^{\mathrm{t}}$ and $\mathrm{b}_{\mathrm{i}}^{\mathrm{t}}$ are the binary control variables in solution $\mathrm{X}_{\mathrm{j}}^{\mathrm{t}}$ and the best solution $B^{t}$ of $B(t)$, respectively. $f\left(X_{j}^{t}\right)$ and $f\left(B^{t}\right)$ represent the objective function values of $X_{j}^{t}$ and $B^{t}$. For example, when $\mathrm{x}_{\mathrm{ji}}^{\mathrm{t}}$ and $\mathrm{b}_{\mathrm{i}}^{\mathrm{t}}$ are 0 and 1 , and $\mathrm{f}\left(\mathrm{X}_{\mathrm{j}}^{\mathrm{t}}\right)$ is larger than $f\left(B^{t}\right)$, the rotation angle $\Delta \theta_{j i}^{t}$ is updated according to the following conditions:

a) if the Q-bit is in the first or third quadrant in 
Fig. 1, the value of $\Delta \theta^{\mathrm{t}} \mathrm{ji}$ is set to a positive value or $+\theta$ to increase the probability of the state " 1 ";

b) if the Q-bit is in the second or fourth quadrant, the value of $\Delta \theta^{\mathrm{t}} \mathrm{ji}$ is set to a negative value or $-\theta$ to increase the probability of the state " 1 ".

It is noted that the same lookup table can be used for the maximization problem.

Tabel 1. Look up tabel of rotation angel

\begin{tabular}{|c|c|c|c|c|}
\hline$x_{j i}^{t}$ & $b_{i}^{t}$ & Quadrant & $f\left(X_{j}^{t}\right) \leq f\left(B^{t}\right)$ & $\Delta \theta_{j i}^{t}$ \\
\hline 0 & 1 & I/III & false & $+\theta$ \\
\hline 0 & 1 & II/IV & false & $-\theta$ \\
\hline 1 & 0 & I/III & false & $-\theta$ \\
\hline 1 & 0 & II/IV & false & $+\theta$ \\
\hline 0 & 1 & $\times$ & true & 0 \\
\hline 1 & 0 & $\times$ & true & 0 \\
\hline 0 & 0 & $\times$ & $\times$ & 0 \\
\hline 1 & 1 & $\times$ & $\times$ & 0 \\
\hline
\end{tabular}

9. Store the best solution into $\mathrm{B}(\mathrm{t})$ :

The best solution among $\mathrm{X}(\mathrm{t})$ and $\mathrm{B}(\mathrm{t}-1)$ is stored to $\mathrm{B}(\mathrm{t})$.

10. Check whether the stopping conditions are met:Terminate if the stopping conditions are met; else goto Step5.

\section{QEA-UC Approach}

The QEA-UC approach proposed in [18] starts by initializing a group of Q-bit individuals with all Q-bit values set as $[\sqrt{0.5} \sqrt{0.5}]^{T}$. At generation $\mathrm{t}$, each $\mathrm{Q}-$ bit individual $q_{g}^{t}$ is represented in (11) and then observed to create a solution $U_{g}^{t}$ of the UC problem in (12), which is a $N \times H$ matrix with binary elements $u_{g n h}^{t}, n=1,2, .$. and $\mathrm{h}=1,2, \ldots, \mathrm{H}$ for $\mathrm{N}$ units in $\mathrm{H}$ scheduling hours. Constraint handling as described in [18] is applied to ensure that feasible unit schedules are produced. Based on each feasible unit schedule, the active power output schedule is determined by an economic dispatch procedure. The dis patch result of each unit schedule is used to evaluate the fitness of the corresponding Q-bit individual. The best solution of unit schedule is selected and then a new group of the Q-bit individuals is generated. The optimization process is repeated until the predefined maximum generation is exceeded:

$$
q_{j}^{t}=\left[\begin{array}{cccc}
\alpha_{j 11}^{t} & \alpha_{j 12}^{t} \cdots & \alpha_{j 1 H}^{t} \\
\vdots & \ddots & \vdots \\
\alpha_{j N 1}^{t} & \alpha_{j N 2}^{t} & \cdots & \alpha_{j N H}^{t}
\end{array}\right]
$$

$$
U_{j}^{t}=\left[\begin{array}{ccc}
u_{j 11}^{t} & u_{j 12}^{t} \cdots & u_{j 1 H}^{t} \\
\vdots & \ddots & \vdots \\
u_{j N 1}^{t} & u_{j N 2}^{t} \cdots & u_{j N H}^{t}
\end{array}\right]
$$

\section{CASE STUDIES}

According to local typical daily data, a optimal scheme can be achieved through the model above. The typical daily data includes local day light intensity curve, environmental temperature curve, wind speed curve, local gas price, the technical performance parameters (rated power, power characteristic curve, operation \& maintenance costs, fuel consumption characteristics, battery maximu m allowable charge-discharge power, etc) of various distributed generators. Since the wind turbine and pv array has high efficiency and almost no emission, we assume they generate as much power as possible. The environmental temperature and The wind speed, light intensity of a typical day are shown in Fig 1, Fig2 and Fig3. the power output of wind turbine and pv array are presented respectively in Fig 4. And then adjust the output of fuel cell, mic roturbine and the charge or discharge of battery storage to minimize the cost and emission while meeting the electrical load and heat load respectively.

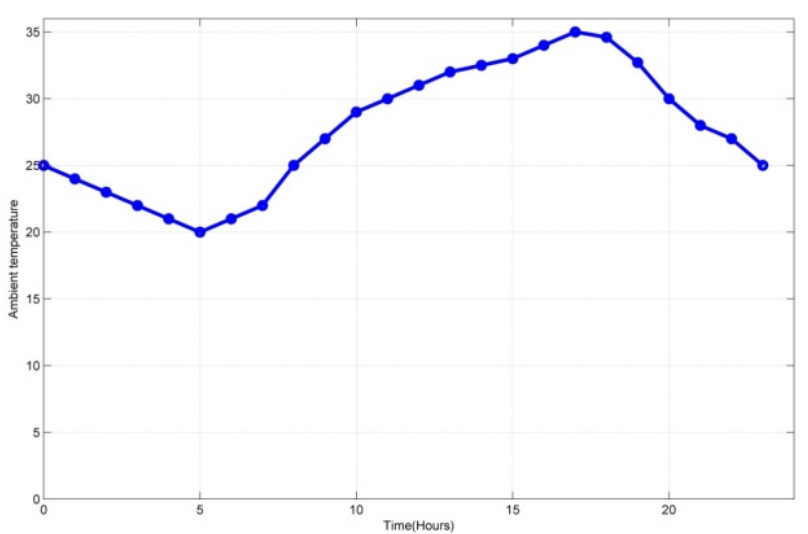

Fig. 1. Ambient temperature

Table 2. The comparison

\begin{tabular}{|c|c|c|c|c|}
\hline Mode & $\begin{array}{c}\text { Purchase } \\
\text { costs }\end{array}$ & $\begin{array}{c}\text { Sale } \\
\text { income }\end{array}$ & $\begin{array}{c}\text { emission } \\
\text { costs }\end{array}$ & $\begin{array}{c}\text { Total } \\
\text { costs }\end{array}$ \\
\hline SA & 494.818 & 74.123 & 117.213 & 1319.634 \\
\hline MFEP & 492.711 & 76.732 & 118.032 & 1321.113 \\
\hline FA & 493.412 & 75.122 & 115.408 & 1316.324 \\
\hline EP & 491.345 & 72.453 & 118.112 & 1318.266 \\
\hline ELR & 493.754 & 76.342 & 117.321 & 1319.991 \\
\hline NSS & 492.186 & 73.765 & 116.432 & 1316.452 \\
\hline MOGA & 490.754 & 81.223 & 115.543 & 1314.213 \\
\hline QEA & 488.333 & 79.653 & 113.213 & 1311.751 \\
\hline
\end{tabular}

Table 3. The comparison before and after optimatization

\begin{tabular}{|c|c|c|c|}
\hline Mode & Purchase costs & Sale income & Total costs \\
\hline A & 502.1 & 79.1 & 1312.1 \\
\hline B & 466.7 & 24.9 & 1284.6 \\
\hline
\end{tabular}

I.J. Intelligent Systems and Applications, 2014, 09, 47-53 
The peak-valley price of electricity is considered for it has aroused a lot of attention for its contribution to reduce the pressure of grid peak regulation and ensure the economy and stability of the system. The purchasing and selling price of electricity is available in [17]. optimal results of different algorithms are shown in Table 2.
When the local typical daily data is given in the model QEA optimal set of economic costs and emissions objective can be achieved and the dispatching scheme when the emissions are not considered is shown Fig5. The results of two modes are compared in the Table 3 and the two modes are two conditions that the battery and peak-vallay price are considered or not considerd.

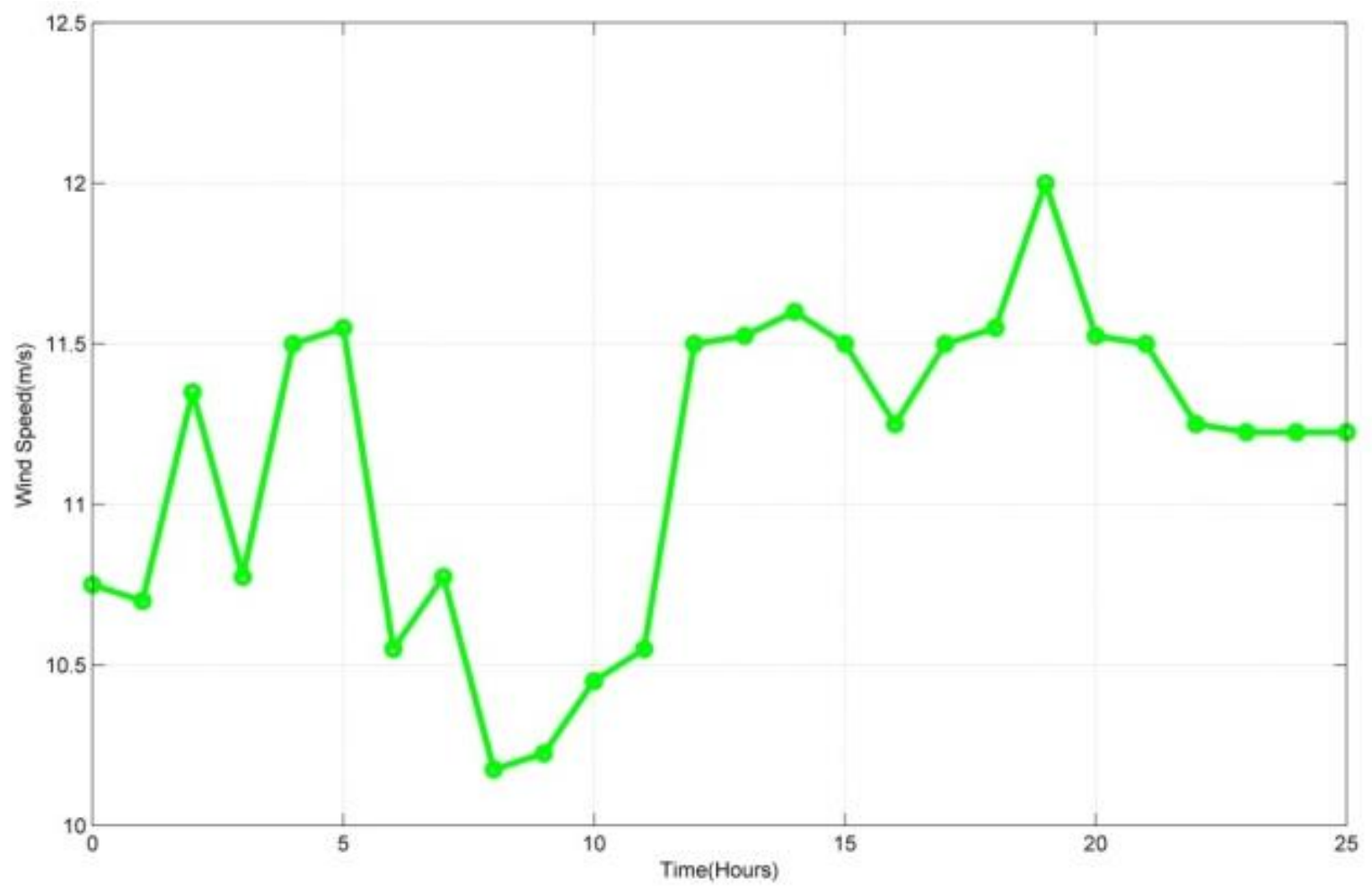

Fig. 2. wind speed

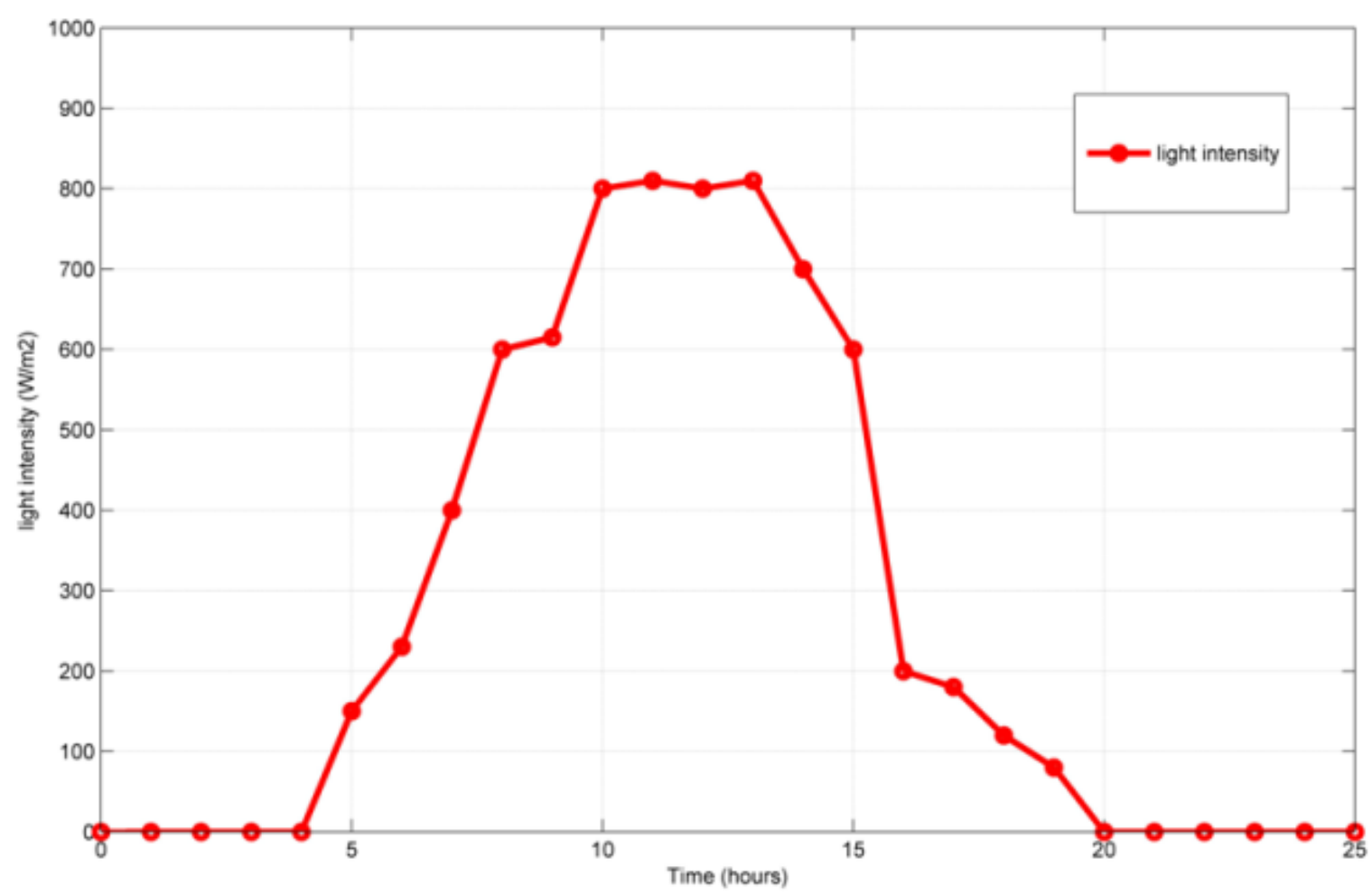

Fig. 3. light intensity 


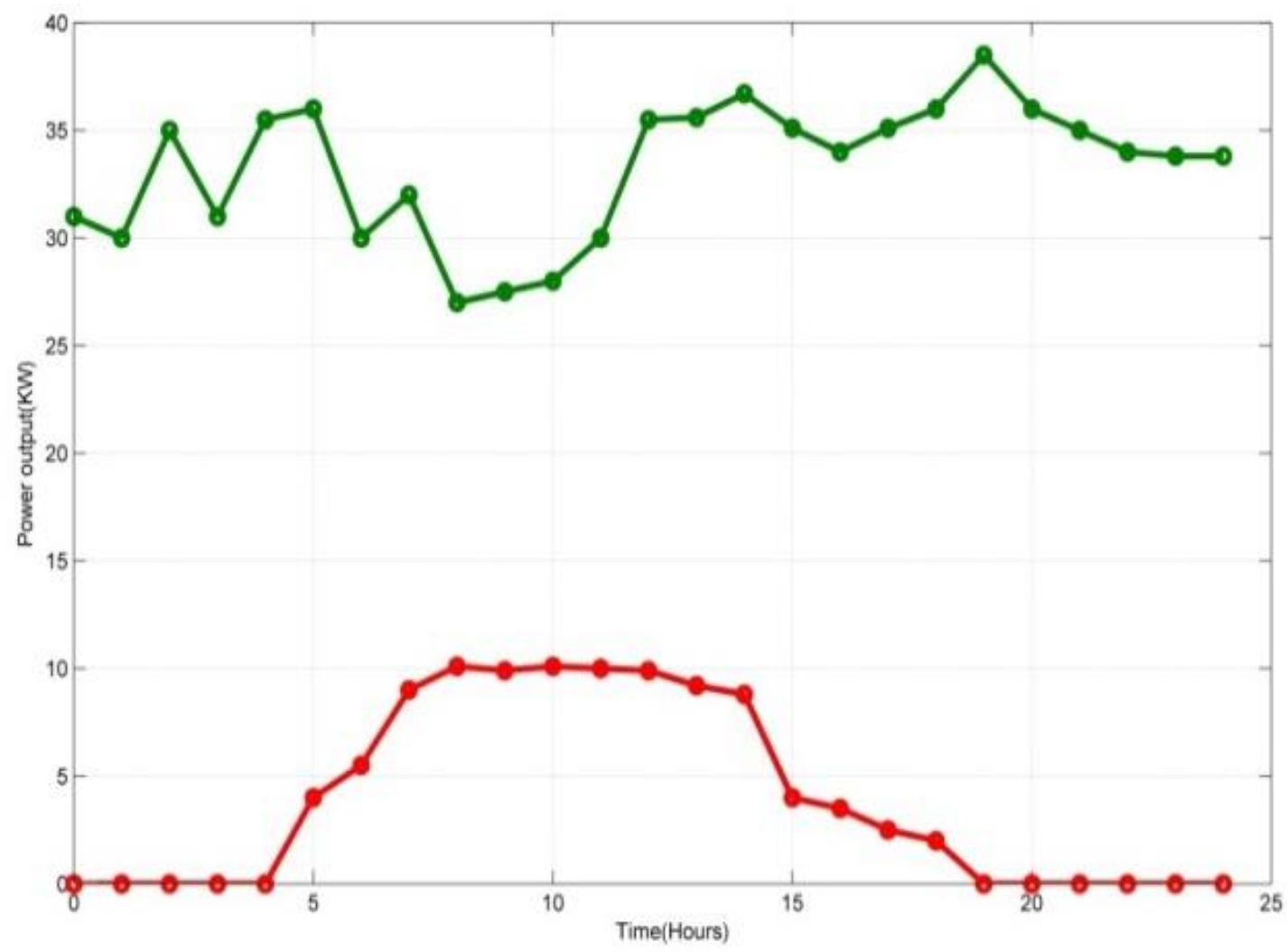

Fig. 4. The Output of WT and PV

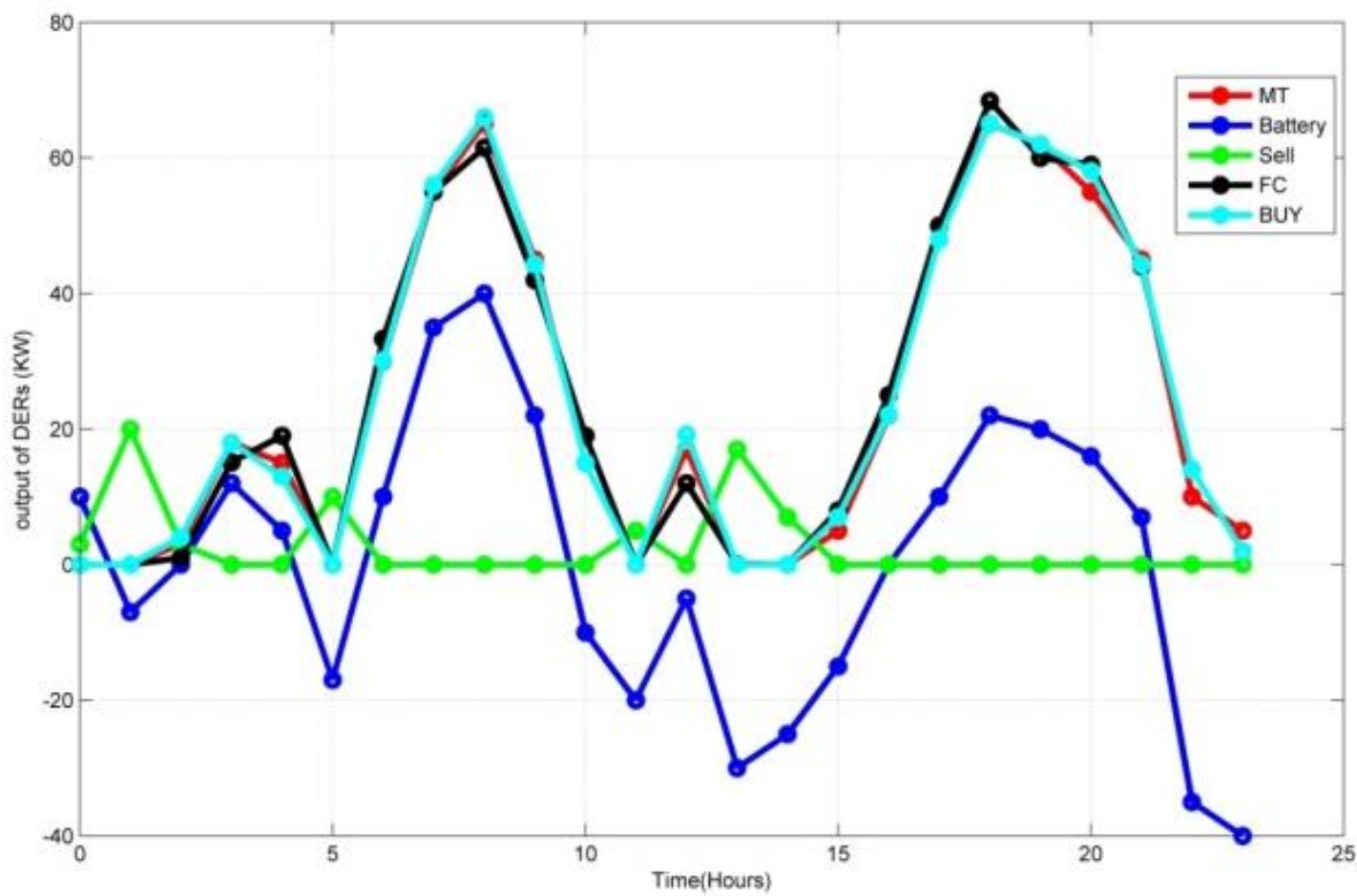

Fig. 5. The dispatch scheme

\section{CONCLUSION}

Based on 24 hour ahead predictions for The microgrid consisting of wind turbine, pv array, CHP system and battery is studied, and Quantum-Inspired Evolutionary
Algorith m is employed to solve the optimal model. It has been found that the QEA-UC algorith $m$ is very powerful and efficient and it outperforms many other methods. Compare the dispatch schemes before and after optimization, the cheaper electricity can be provided to customers in the sight of that the day is considered as the 
optimal period. QEA-optimization is applied to the environmental/ economic problem of the MG, considering the operating cost, fuel cost, depreciation cost as well as environ mental cost. More robust and more actual optimal solution can be developed in the future research.

\section{REFERENCES}

[1] R. Firestone and C. Marnay, Energy manager design for microgrids,Lawrence Berkeley Nat. Lab., CA, Tech. Rep. LBNL-54447, Jan. 2005.

[2] E.Handschin, F.Neise, H.Neumann, et al. Optimal operation of dispersed generation under uncertainty Using mathematical programming $[\mathrm{J}]$. Electrical Power and Energy Systems'2006'28+618 626.

[3] A.D.Hawkes, M.A.Leach. Modelling high level system design and unit commitment for a microgrid[J]. Applied Energy'2008+1 13.

[4] Mohamed, Faisal A. System modelling and online optimal management of MicroGrid using Mesh Adaptive Direct Search $[\mathrm{J}]$. International Journal of Electrical Power and Energy Systems.PAGE398-407 2010-6.

[5] Milo, Aitor Optimization of an experimental hybrid microgrid operation: Reliability and economic ssues[CA].2009 IEEE Bucharest PowerTech: Innovative.

[6] Mohamed, Faisal A.;Koivo, Heikki N. MicroGrid online management and balancing using multiobjective optimization[CA] 2007 IEEE Lausanne POWERTECH, Proceedings VOL ISSU PAGE 639-644, 2007

[7] Mohamed, Faisal A. Multiobjective optimization using modified game theory for online management of microgrid[J].European Transactions on Electrical Power VOL 21 ISSU 1 PAGE 839-854 DATE January 2011

[8] C. M. Huang., H. T, Yang, C. L. Huang, Bi-objective power dispatch using fuzzy satisfaction-maximizing decision approach.IEEE Trans. Power Sysl.. Vol. 12. Nov. 1997, pp. 1715-1721.

[9] El-Sharkh, M.Y., Rahman, A., and Alam, M.S., etc., "Thermal energy management of a CHP hybrid of wind and a grid-parallel PEM fuel cell power plant," in Proc. IEEE-PES Power Systems Conference and Exposition, March 2009, pp. 1-6.

[10] Feng Zhi-bing and Jin Hong-guang, $\bar{A}$ Part-load Performance of CCHP with Gas Turbine and Storage System," Proceeding of the CSEE, vol. 26, no. 4, pp. $25-$ 30, April 2006.

[11] Gu, W. Wu, Z. Yuan, X. Microgrid economic optimal operation of the combined heat and power system with renewable energy. IEEE PES General Meeting, PES 2010 VOL ISSU PAGEDATE 2010.

[12] Miller. N, Sanchez-Gasca.J. Price, W. Delmerico.R. Dynamic modeling of GE 1.5 and $3.6 \mathrm{MW}$ wind turbinegenerators for stability simulations. IEEE Power Engineering society General Meeting, 3(13-17), pp.19771983, July 2003.

[13] Chakraborty, S. and Simoes, M.G., PV-Microgrid Operational Cost Minimization by Neural Forecasting and Heuristic Optimization, in Proc. IEEE-IAS Annul Meeting, Oct. 2008, pp. 1-8.

[14] Velumani, S. Proposal of a hybrid CHP system: SOFC/microturbine/absorption chiller. International Journal of Energy Research. VOL 34 ISSU 12 PAGE1088-1095 DATE October 2010
[15] Abido M. A Environmental/Economic Power Dispatch Using Multiobjective Evolutionary Algorithms, IEEE TRANSACTIONS ON POWER SYSTEMS, vol. 18, No. 4 November 2003 p. $1529,1537$.

[16] Konak.Abdullah.Multi-objective optimization using gene tic algorithms: A tutorial. Reliability Engineering and System Safety VOL 91 ISSU 9 PAGE 992-1007 DATE September 2006.

[17] NIU Ming,HUANG Wei,GUO Jiahuan,SU Ling. Research on Economic Operation of Grid-Connected Microgrid. Power System Technology. Vol.34 No.11,2010.PAGE 3842.

[18] T. W. Lau, C.Y.C., Quantum-Inspired Evolutionary Algorithm Approach for Unit Commitment. IEEE TRANSACTIONS ON POWER SYSTEMS, 2009. 24(3).

[19] T. W. Lau, C. Y. Chung, K. P. Wong, T. S. Chung, and S. L. Ho,"An Advanced Quantum-inspired evolutionary algorithm approach for unit commitment," IEEE TRANSACTIONS ON POWER SYSTEMS, VOL. 26, NO. 2, MAY 2011

\section{Authors' Profiles}

Ebrahim Zare juybari received B.Sc degree from University of Mazandaran ,iran in 2011, he received M.Sc degree from University of Science and Technology, iran in 2013. Currently, he is Research on calculation of transient flow in high-voltage lines.

Seyed Mehdi Hosseini received B.Sc degree from University of Mazandaran ,iran in 2002, he received M.Sc and Ph.D degree from Iran University of Science and Technology in 2002,2009 respectively.Currently, he is conducting research work on Reliability of Distribution Systems, Distributed Generation, FACTS Devices.

How to cite this paper: Ebrahim Zare juybari, Seyed Mehdi Hosseini,"Optimization of Microgrid Using Quantum Inspired Evolutionary Algorithm", International Journal of Intelligent Systems and Applications(IJISA), vol.6, no.9, pp.47-53, 2014. DOI: 10.5815/ijisa.2014.09.06 